\title{
EL ESTUDIO DE LAS ARMAS EN EL SIGLO XVIII: LA REAL ACADEMIA DE LA HISTORIA Y EL HALLAZGO DE UNA ESPADA RENACENTISTA EN PEÑAFIEL
}

\author{
POR
}

\author{
ALVARO SOLER DEL CAMPO
}

\section{RESUMEN - ABSTRACT}

En 1751 el rey Fernando VI solicitó a la Real Academia de la Historia un informe sobre el hallazgo fortuito de una espada renacentista en Peñafiel (Valladolid). Este informe permite aproximarnos al estudio de las armas durante el siglo XVIII, en el que las explicaciones legendarias conviven con planteamientos modernos personalizados por Ignacio de Luzán. Destaca igualmente por la incorporación de una detallada documentación gráfica de dicha espada.

In 1751 the king Fernando VI ordered to the Real Academia de la Historia a report on the fortuitous finding of a renaissance sword in Peñafiel (Valladolid). This report allows an approach to arms studies in the eighteenth century, when legendary arguments coexisted with a modern reasoning personalized by Ignacio de Luzán. It is also important an enclosed drawing as its accurate record.

\section{PALABRAS CLAVE - KEY WORDS}

Armas blancas. Espadas. Historiografía. Dibujos. Fernando VI. Real Academia de la Historia. Ignacio de Luzán. Real Armería.

White arms. Swords. Historiography. Drawings. Fernando VI. Real Academia de la Historia. Ignacio de Luzán. Real Armería.

La Real Academia de la Historia conserva un interesante volumen manuscrito que contiene el parecer de varios académicos sobre una espada renacentista hallada a finales del mes de noviembre de 1751 en el convento de San Juan y San Pablo de Peñafiel (Valladolid). El manuscrito es de gran interés porque manifiesta los conocimientos contemporáneos sobre la materia y porque ofrece información sobre los métodos de análisis y de trabajo de los académicos que debieron examinarla. En el primer folio puede leerse lo siguiente:

1752

Legaxo, 30 en $4^{\circ} \quad n^{\circ} 10$

Expediente acerca de la espada que se halló en el centro del muro de un torreón del comb. de S Pablo de Peñafiel, que remitió el Rey a la Academia para que diesse su dictamen. Contiene:

- El papel de remisión del Marq dela Ensenada con fha de 21 de Diz de 1752.

$1^{\circ}$ copia del dictamen que habia dado el P Fr. Martin Sarmiento.

$2^{\circ}$ Copia del Privilegio de dotacion y fundacion del dho comb. por el Inf. D. Juan Manuel. 
Papeles que escrivieron los S. Dominguez Vicente, Hilarion Dominguez, Castillo, Medina, Luzan, Amaya, Dieguez, Campomanes y Milla. Resumen de los informes de peritos e impugnac del P Sarmiento $f$ 24 Copia del Dictamen que dio a S.M. la Academia, entendido por el S Montiano, Director.

Diseño puntual de la misma espada

El hallazgo fue fortuito, pero envuelto en circunstancias que no son fáciles de esclarecer. El convento de San Juan y de San Pablo se encuentra situado junto a las antiguas defensas de la villa, hoy perdidas, que seguían la vega del río Duratón. Gracias al testimonio de Fray Fernando de la Cuesta, miembro de la comunidad y testigo de la aparición, sabemos que el convento sufrió en 1751 un incendio que hizo necesario levantar un ala de nueva planta. Para ello comenzó a ser desmontado uno de los dos torreones cuadrados de la fortificación, levantados en piedra y argamasa, que subsistían junto a la ribera. La consistencia de la construcción obligó a recurrir a barrenos de pólvora, operación durante la cual se halló un hueco revestido de piedra, donde se encontró un madero y sobre él la espada con su vaina.

Fernando VI (1746-1759) se interesó por el hallazgo y ordenó al Marqués de la Ensenada que remitiera la espada a la Real Academia de la Historia para que diese su dictamen ${ }^{1}$.

Como es sabido, la Academia tuvo su origen en las tertulias que se realizaban en 1735 en el domicilio del abogado y empresario Julián Hermosilla. En 1735 fueron aprobadas sus constituciones y en 1736 se autorizó que tuviera su primera sede en la Real Biblioteca. Poco después se pidió la protección del rey Felipe V (1700-1746), obtenida por Real Cédula de 18 de Abril de 1738 en el que fueron aprobados sus estatutos quedando legalmente constituida como tal. Se comenzó a formar la biblioteca y a reunir cuantos objetos pudieran dar testimonio del pasado e ilustrarlo, mostrando desde sus orígenes un interés especial por los monumentos de la antiguiedad, considerados como documentos fundamentales para el conocimiento de la Historia. Este planteamiento suponía que el primer objetivo de la institución fue la protección y el estudio del patrimonio histórico. Desde el primer momento la actividad de la Academia se encaminó en este sentido bajo la dirección del escritor Agustín Montiano y Luyando, quién apoyó la realización de viajes concebidos como expediciones científicas. En 1752, año del informe, tuvo lugar el primer viaje impulsado desde la Academia, encargado a Luis Velázquez, Marqués de Valdeflores, para conocer las antigüedades de España y recoger los monumentos más importantes. También es el año de la instrucción del Marqués de la Ensenada sobre la protección y conservación de antigüedades. En este momento había por tanto un gran interés por las cuestiones arqueológicas y por el recurso a métodos correctos de documentación como el dibujo preciso de los monumentos ${ }^{2}$.

En la actualidad se desconoce el paradero de la espada, pero los informes de los académicos y un dibujo completo a lápiz de la misma, realizado sobre una hoja desplegable que cierra el volumen ${ }^{3}$, permiten describirla con exactitud. En él muestra el anverso y el reverso de la espada precedidos por el siguiente encabezamiento:

Diseño dela Espada que se halló sobre un madero puesta en un proporcionado hueco dentro del Macizo de una delas Paredes de un Torreonque se demolia en el Convento de San Juan y San Pablo de Religiossos Dominicos dela Villa de Peñafiel

El dibujo fue hecho a escala real, tanto por las dimensiones del $\operatorname{arma}^{4}$ como por una breve anotación en el reverso, en la que se especifica que se trata de un Dibuxo exacto de la

1 Real Academia de la Historia. Ms. 9-5930. Ciento ocho folios numerados. Alto: $31.3 \mathrm{~cm}$. Ancho: $22 \mathrm{~cm}$

2 Maier (2001). Sobre la actividad de la Academia ver: Almagro Gorbea (1999); Tesoros, (2001).

3 Folio $108^{\circ}$. Alto $120 \mathrm{~cm}$. Ancho $38.6 \mathrm{~cm}$.

4 Longitud total: $96.5 \mathrm{~cm}$. Diámetro del pomo: $6 \mathrm{~cm}$. Ancho del arriaz: $18.1 \mathrm{~cm}$. Longitud de la hoja hasta el arriaz: $81.2 \mathrm{~cm}$. Ancho máximo de la hoja: $7 \mathrm{~cm}$. 


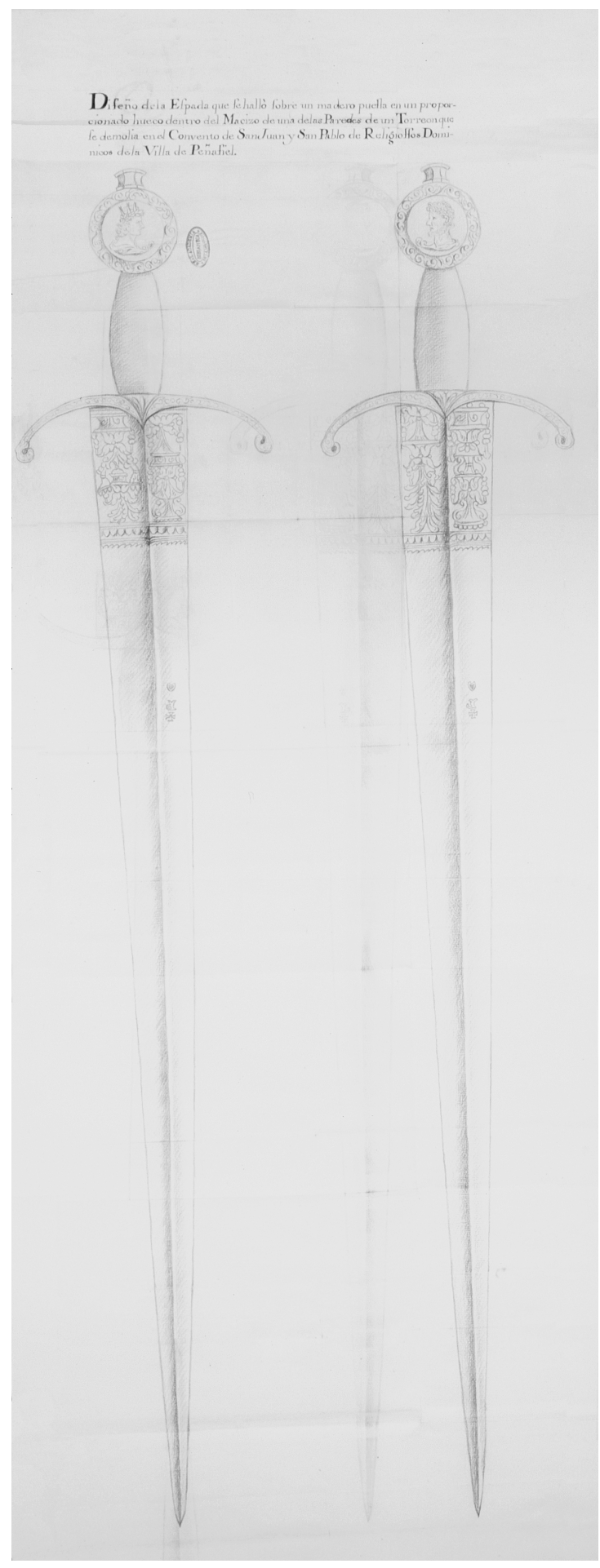

Fig. 1.- Dibujo de la espada hallada en el convento de San Juan y San Pablo de Peñafiel (Valladolid). Madrid, 1752. Real Academia de la Historia. Madrid. Ms. 9-5930. 


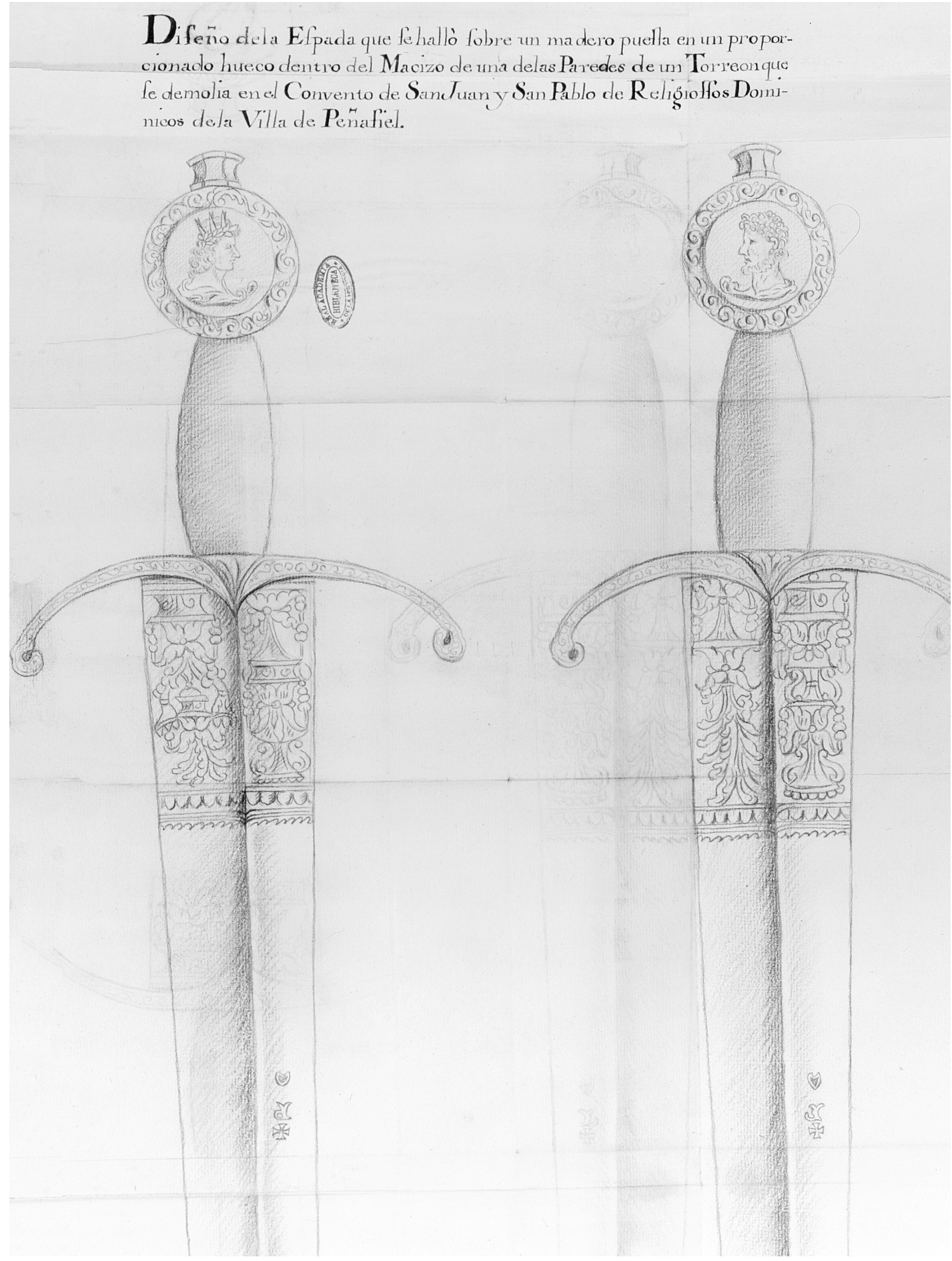

Fig. 2- Detalle de la empuñadura. 


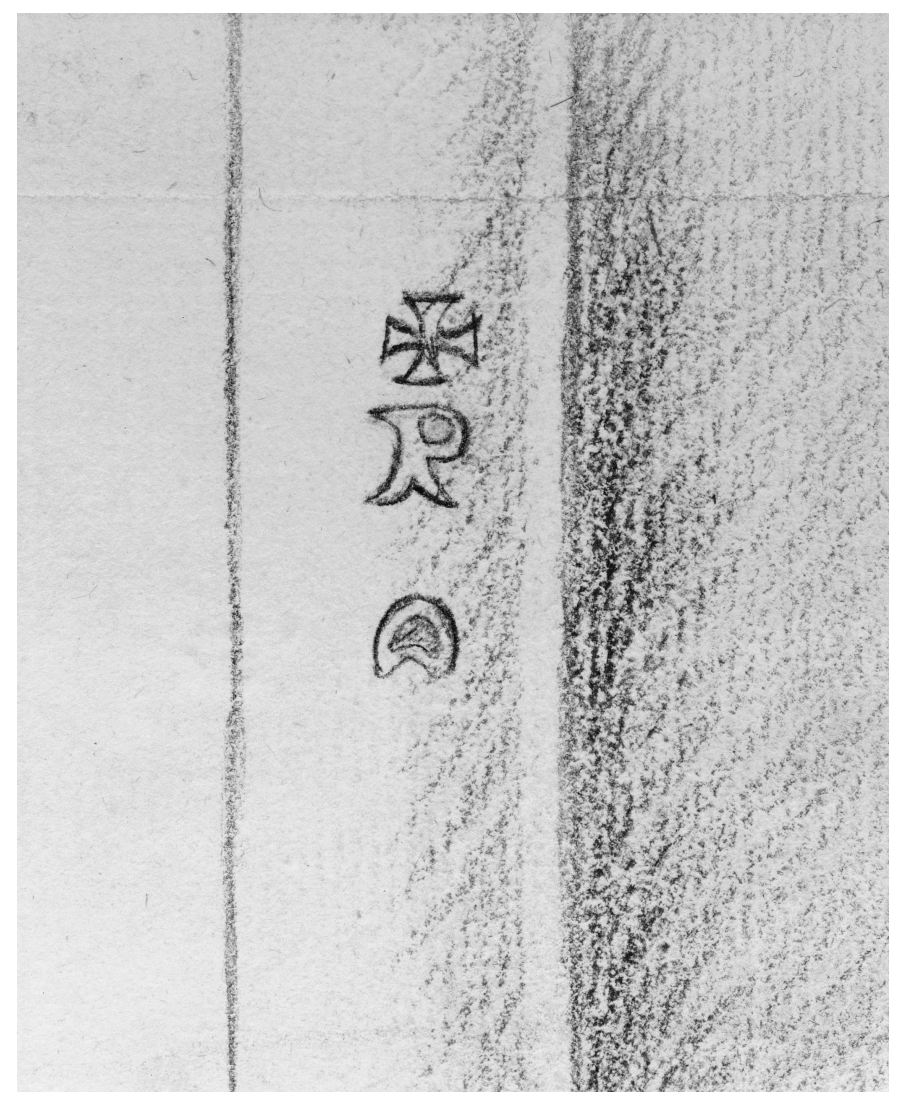

Fig. 3.- Detalle de las marcas. Escala 1:1.

Espada. La empuñadura está compuesta por un pomo redondo plano, macizo ${ }^{5}$, coronado por un botón octogonal o hexagonal, puño ensanchado en el centro, arriaz con escudete central apuntado y extremos curvos avolutados. La hoja es triangular, de cuatro mesas, con arista central relevada. En ambas caras muestra como marcas un punzón acorazonado, una P bífida en el extremo inferior y una cruz potenzada, todas ellas dispuestas en vertical.

La espada estaba ricamente decorada mediante un pomo dorado ${ }^{6}$, cincelado y/o grabado ${ }^{7}$, al igual que el arriaz, puño forrado de terciopelo carmesí ${ }^{8}$, y hoja dorada y grabada en el sector superior del tercio fuerte 9 . En el dibujo el pomo muestra en ambas caras una banda perimetral conteniendo hojarasca o espirales que limitan un campo circular. En el anverso representa el busto, en perfil derecho, de un hombre imberbe que ciñe una corona de laurel con tres radiantes, mientras que en el reverso alberga el busto, en perfil izquierdo, de un hombre barbado con pelo rizado, ambos inspirados posiblemente en una serie de medallas con marcado carácter clásico ${ }^{10}$. La decoración del arriaz se limita a hojarasca o espirales en consonancia con las bandas del pomo. La hoja se encontraba profusamente decorada en el tercio

\footnotetext{
5 Fol. 25v.

6 Fols. $38^{\circ}, 46 \mathrm{v}, 88^{\circ}$.

7 Fols. $6^{\circ}, 49^{\circ}, 76 \mathrm{v}, 88^{\circ}$

8 Fol. 88v.

9 Fols. 16V, 46v.

10 Rasgos similares pueden apreciarse en Roville (1553: 70).
} 
fuerte mediante candelabros limitados en el extremo inferior por bandas y festones. La espada estaba acompañada por una vaina, según refiere el dictamen de la Academia gracias al testimonio de fray Fernando de la Cuesta ${ }^{11}$. Ningún académico se fijó sin embargo en ella, por lo que es posible que ni siquiera llegaran a verla.

La Academia aborda el estudio de la espada cuando las obras sobre armas blancas antiguas en España pueden considerarse casi inexistentes, aunque a partir de este momento comenzó a surgir un relativo interés por los legados del pasado y su origen. Esta situación incluso es palpable en colecciones de primera importancia como la Real Armería de Madrid, donde debemos esperar a finales de siglo para ver publicado un inventario por vez primera ${ }^{12}$. En el resto de Europa la atención se centra en el desarrollo de las armas contemporáneas mediante tratados sobre su fabricación y perfeccionamiento técnico, tipología, patrones decorativos o manuales de uso. El eco de las armas antiguas es tenue, como puede apreciarse incluso en la Enciclopedia de Diderot, contemporánea al hallazgo de Peñafiel. En este contexto llama particularmente la atención la precisión «arqueológica» del dibujo que acompaña al volumen. El planteamiento de la Real Academia de la Historia al encargarlo es novedoso y acorde con sus planteamientos, ya que fue realizado con fines de documentación y estudio, reflejando con la mayor veracidad posible sus dimensiones, los detalles decorativos, la documentación de las marcas o el tratamiento de las sombras insinuando formas o secciones. Estos rasgos hacen de él un documento excepcional, ya que los escasos dibujos de armas blancas antiguas conservados no sueles responder a estos fines, al tratarse, por lo general, de proyectos, modelos artísticos, o instrumentos para control de inventarios ${ }^{13}$.

El informe de la Academia estuvo basado en el examen de la espada y de la documentación remitida sobre las circunstancias del hallazgo. Esta última fue determinante en el estudio y consideración de la misma ante la ausencia de entendidos en la materia. En el informe preliminar, el polígrafo y religioso Martín Sarmiento (1695-1772) concedió mayor importancia a la documentación por lo que la fechó en principios del siglo XIV y atribuyó su propiedad al infante don Juan Manuel (1282-1347). Reconoció sin embargo no ser experto en la materia, por lo que aconsejó solicitar la opinión de la Real Armería.

Tras el dictamen de Sarmiento se consultó a seis peritos en la materia, el primero a cargo de Pedro Rodríguez ${ }^{14}$, armero de la Real Armería, quien después de desmontar la espada consideraba que la hoja estaba «hecha en el Imperio» ${ }^{15}$, no mostraba marcas en el recazo y que sólo conocía una espada de este tipo en la colección real ${ }^{16}$.

Destaca también el sexto informe, que aboga por una procedencia alemana o borgoñona, sitúa cronológicamente el arma a finales del siglo XV o inicios del XVI, discute las marcas y cree identificar en los bustos del pomo al emperador Maximiliano I y al rey Felipe I el Hermoso. Por la cronología propuesta no cree que hubiera pertenecido a D. Juan Manuel, sino a

11 Fol. 69v.

12 Abadía (1793).

13 Para referencias sobre el tema y modelos contemporáneos ver Godoy (1988).

14 Espadero con tienda en Madrid deja sus negocios para mejor desempeño de su trabajo en la Real Armería, dependiente entonces de la Real Caballeriza. El 12 de septiembre de 1749, el Caballerizo Mayor, Duque de Medinaceli, le nombra guarnecedor de espadas de la Real Caballeriza. En Marzo de 1760 es comisionado director para la limpieza de las armas de la colección, ascendiendo a armero interino en agosto del año siguiente. En marzo de 1767 es nombrado armero de número y el 1 de abril de ese mismo año jura plaza de armero de la Real Armería (Archivo General de Palacio, Caja 898/3).

15 Fol. 24v.

16 Pedro Rodríguez se refiere a las espadas G.23 o G.24 de la Real Armería, cuyas hojas, triangulares, se caracterizan por una arista central relevada y decoración grabada al agua fuerte en el tercio fuerte (Valencia de Don Juan, 1898: G.23 y G.24, 205-209). En esta época la Real Armería seguía estando fundamentalmente ordenada como en tiempos de Felipe II, es decir, las armas se agrupaban según sus propietarios, los cual supone un orden cronológico que ayudaría a explicar el atinado informe de Pedro Rodríguez. 
un descendiente homónimo de éste, caballero del Toisón de Oro, que fue enterrado en 1500 en la capilla del convento.

El informe de los peritos fue seguido por los pareceres de los académicos Hilarión Domínguez, Pedro Rodríguez Campomanes, Lorenzo Diéguez y Castrillo, Juan de Milla y de la Cruz, Amaya y José Domínguez Vicente, quienes fundamentalmente siguen la opinión de Sarmiento condicionados por la documentación escrita, de forma que señalan como propietario al infante Don Juan Manuel, e incluso se pretende ver el retrato de Alfonso X (12211284) en el anverso, o se proporciona una interpretación fantástica de las marcas.

Entre los académicos destaca el parecer del escritor Ignacio de Luzán (1702-1754), quién al contrario que sus compañeros sigue el parecer del sexto perito. La postura de Luzán ante la espada es también nueva por su modernidad y rigurosidad, a pesar de algunas interpretaciones más o menos fantásticas como la lectura de las marcas, que estarían en conjunción con la decoración del pomo remitiendo implícitamente a una iconografía relacionada con la Casa de Austria. En su planteamiento se aprecia un enfoque próximo a una moderna catalogación, ya que su interés se centra en la cronología, procedencia, propietario y razones del ocultamiento o circunstancias del hallazgo. Para ello no duda, ante la ausencia de otra documentación, en buscar la respuesta en la propia espada. Esta postura es importante porque denota una actitud científica que le llevará a aproximarse a una correcta valoración de la pieza. Su argumentación difiere de las razonadas por otros académicos por la claridad de su pensamiento, que propicia el apoyo momentáneo de su tesis.

El análisis de Luzán sugiere que estaba más cerca de los planteamientos de la Ilustración de sus compañeros, lo cual le permitió aproximarse más correctamente a la espada. Como espíritu ilustrado se interesa por el empleo de una metodología adecuada, es consonancia con su preocupación por cuestiones teóricas que atañen a la actividad historiográfica. Por ello se preocupa por la falta de datos al no querer incurrir en ligereza, lo que le lleva, como método de estudio que debería estar basado en la exactitud documental, al análisis formal, estilístico, de las técnicas decorativas y de las marcas. Tras ello descarta correctamente una adscripción plenomedieval y apunta que debió pertenecer a un caballero de la Orden del Toisón de Oro hacia finales del siglo XV y a principios del XVI, tomando buena nota de la cronología propuesta por el armero Pedro Rodríguez. Aunque Luzán se deja llevar por el afán de querer explicar el significado de las marcas, el encuadre cronológico adoptado si es correcto. Los festones, hojarascas o espirales y candelabros remiten al norte de Italia hacia 1500. Aunque no conozco paralelos que agrupen las tres marcas, algunas de ellas cuentan con antecedentes de dicha procedencia. Diversas formas de P bífida están presentes en piezas italianas desde mediados del siglo XV, al igual que algunas marcas acorazonadas ${ }^{17}$.

La cronología propuesta y su hallazgo en el convento de San Pablo inducen a Luzán a apuntar como posible propietario a D. Juan Manuel (m. 1535), Señor de Zevico de la Torre y de Belmonte de Campos, Contador Mayor de Castilla, investido 123 Caballero del Toisón de Oro en 1505 por Felipe el Hermoso en el décimo séptimo capítulo de la Orden ${ }^{18}$. Aunque por la riqueza de la espada bien podría haber pertenecido a tan ilustre caballero, nada permite asegurarlo con certeza. Si bien es cierto que su capilla funeraria se encuentra en dicho monasterio, los oscuros datos sobre el hallazgo y el supuesto ocultamiento no permiten una relación entre ambos, ya que la cerca derruida se encontraba presumiblemente alejada de la capilla, a juzgar por la situación de la nueva ala del edificio tal y como se aprecia hoy en día.

Tras sus breves pero básicamente acertadas conjeturas, fuera de la línea del resto de los académicos, Luzán cierra el texto con una formal pero ilustrada declaración de principios,

17 Confrontar: Valencia de Don Juan, 1898: G.23 205-208; Gynwell, 1959:73; Mann, 1962: nº A. 888, pl. 45, 431432; Boccia y Coelho, 1975: no 95-96, 276, 335-336; Godoy, 1991: 105-107; Godoy, 1992: 112-115.

18 Pinedo y Salazar (1787:133). 
expresando su preocupación por la necesidad de disponer de más datos y por su depuración en búsqueda de la verdad, inquietudes propias de su tiempo en contraposición a la historiografía barroca ${ }^{19}$.

El dictamen final de la Academia (19 de enero de 1753) recogió el proceso de estudio de la espada, desde la tesis de Sarmiento, inicialmente aceptadas, al cambio de opinión tras el lógico informe de Luzán, descartado porque las circunstancias del hallazgo no apoyaban $a$ priori una cronología próxima al año 1500. Por ello se pidió el parecer dentro de la comunidad de San Juan y San Pablo de Fray Fernando de la Cuesta, a cuyo juicio el muro en el que se ocultaba la espada debería ser considerado de la época de fundación del convento. Ante esta aseveración, la Real Academia resolvió que la espada sólo podía haber pertenecido al rey Alfonso X el Sabio y ocultada para perpetuar su memoria, lo cual descartaba la atribución al infante Don Juan Manuel o a su biznieto. La cabeza coronada del pomo se interpretó como un retrato de Alfonso X y la restante como posibles retratos del elector de Tréberis o de Felipe de Suabia. Llama la atención constatar cómo las discusiones que condujeron a las atribuciones a estos personajes de deben al eco del «carácter imperial» que desprendía la espada, pero en este caso erróneamente dirigido hacia las aspiraciones imperiales de Alfonso $\mathrm{X}$ por su entronque con la Casa de Suabia.

19 Sobre el marco historiográfico contemporáneo ver Maravall (1972). 


\title{
APÉNDICE
}

\author{
Conjeturas de Ignacio de Luzán
}

\section{Conjeturas}

Sobre la espada hallada en Peñafiel

Lo que se puede preguntar, y desear saber acerca desta Espada, me parece que se reduce al tiempo, y lugar en que se fabricó, y a las personas que la dieron, la recibieron, y la depositaron en la Torre de Peñafiel; esto es, que antigüedad tiene esta espada, donde, y por quien se hizo, quien fue el dueño de ella, y quien la dexó colgada, o escondida en la pared de aquella Torre.

Para descubrir todas estas circunstancias, faltandonos por ahora los manuscritos de Peñafiel, que talvez nos sacarian de toda duda, no hay otros medios, que la hechura, y tamaño de la misma Espada, su Gravado, y dorado, las cabezas buriladas en el pomo, y especialmente algunas marcas, o figuras que hay en la misma espada.

Valiendome de estos medios, y combinandolos con alguna reflexion, diré lo que entiendo como conjetura, que después, teniendo tiempo procuraré corroborar con mas solidos fundamentos.

Y primeramente, venerando como debo la erudición del P. Sarmiento, y de los Eruditos Compañeros S. Académicos, que en la conferencia passada manifestaron ya hacia donde inclinaba su opinión; diré lo que a mi ver no es la Espada, para passar después a decir lo que es, segun mis conjeturas.

Esta Espada no es Gladio Hispano; porque ya ala vista se manifiesta muy moderna su hechura; y porque medida con el pie Romano se ha hallado tener de largo dos pies, y doce onzas: y lo largo del Gladio Hispano no llegaba a dos pies; bien es verdad que su figura de obelisco, y su firmeza la hacen en cierto modo parecida al gladio hispano, quando todas las demas circunstancias se oponen.

Tampoco es, a mi ver, espada hecha en España, porque su forma, su dorado, y gravado manifiestan mas presto aver sido hecha en Alemania, o en Borgoña.

Las Cabezas no son tampoco, como supone el P. Sarmiento, una de S. Fernando, u de Fernando IX. y otra de D. Juan Manuel: pues repugna la corona de laurel ademas dela radiada, que tiene la una; y la desnudez del cuello, y trage Romano, que tienen ambas; no aviendose usado en España en aquellos tiempos el ressaltar a nuestros Reyes con corona de Laurel, y con el ayre y trages de Emperadores Romanos y así es una suposición voluntaria, que no puede admitirse, sin muchas pruebas convincentes.

Mucho menos puedo convenir en que sea R. la que es P. y que esto indique el nombre de un Artífice famoso llamado Raymon o Remon: porque es también aserción puram voluntaria, y repugnanse alo que vemos que es una $P$. y no una $R$.

Asimismo es conjetura muy debil la que esta Espada fuesse la de D. Juan Manuel así porque no hay prueba, mas que la semejanza de la Espada del Escudo de los Manueles, que trae Argote, y el averse hallado en Peñafiel, cuyo convento fundó aquel (Infante) Señor ${ }^{20}$.

La semejanza dela Espada no prueba nada si primero no se prueba que D. Juan Manuel usó ya de aquel escudo de Armas: Las que yo creo posteriores por ser parlantes, y a mi ver ideadas o sugeridas por algun Rey de Armas Franceses, u Borgoñon, como lo manifiesta el aver formado armas parlantes de la voz española Mano, y dela voz francesa aisle; que pronunciada él, forma el nombre de Manoel. Fuera de que el P. Menestrier trae este mismo escudo delos Manueles, con una espada de hechura muy distinta. Y esta forma de Armas parlantes, y tan compuestas no es a mi ver del siglo de D. Juan Manuel, sino muy posterior. Y a todo esto se añade lo que diré después, que si es verdadero, u fundado destruirá enteramente la opinión de que fuese espada de D. Juan Manuel.

Passando aora brevemente a decir lo que es la espada, segun mis conjeturas: (Digo que ella es) ${ }^{21}$. No quiero dexar de confessar, que me ha motivado mucho a hacerlas la noticia que oí en la ultima junta a nuestro erudito compañero el S. D. Juan de Amaya, y a una penetración ingeniosa del S. Conde de Torrepalma que acercandose mucho ala Verdad, según lo que yo pienso, imaginó ver en una de las Marcas no un Corazón, si no una Mitra.

Llegando pues a expresar mis conjetu.. soy de parecer, que esta Espada, es propiamente hecha para un Caballero del Toyson a fines del siglo decimoquinto, o principios del Decimo sexto. Que lo que parece

20 Tachado en el original.

21 Tachado en el original. 
corazon no lo es, sino el Bonete Ducal de los Duques de Borgoña, que la Cruz, que se ve debaxo dela P. es propiamente la Cruz, o Aspa de S Andres Santo Tutelar dela Orden del Toyson.

Que la P. es la inicial del nombre Philippus o Phelipe, ya sea Phelipe el Bueno Fundador de la Orden del Toyson en 1429, o Phelipe I Rey de España, antes conde de Flandes; aunque no creo que sea sino el primero.

Que la cabeza con corona radiada, y laurel es de Maximiliano I. Rey de Ungria y Bohemia, y Emperador, que no se coronó: Padre de Phelipe I. y Xefe de la Orden el Toyson por su casamiento con Maria heredera de Borgoña.

Que la otra Cabeza, puede ser de su hijo Phelipe I antes de heredar de su Padre, y por esso está sin corona; aunque puede ser que represente a otra persona, que el Artifice, o el que mando hacer la espada quiso que se figurasse en el pomo.

Que esta espada fue probablemente de D.N. Manuel Caballero del Toyson; y que probablemente con ella le armó Caballero el Emperador Maximiliano, o el que le dio el Toyson: porque es constitución de la Orden, al conferirla, que se arme Caballero el que la recibe, si no lo estubiere.

Que el referido D. Manuel muerto en 1500 \& y enterrado en la Capilla de Peñafiel, que el mismo fundo, según las noticias con que me ilustró el Sr. Amaya; ,mandaria sin duda, que esta Espada, dadiva de un Emperador, o con la que se habia armado Caballero, y por estas razones digna de su estimación, se colocase en el lugar de su entierro, y quiza para preservarla mas de las injurias del ayre, del tiempo, y de otras, mandaria que la encerrasen en el nicho donde se ha hallado.

Estas Conjeturas, que tumultuariamente he puesto en el papel esta mañana, necesitan de apoyos, y fundamentos; y para hallarlos, necesito yo de tiempo, y de revolver libros. Si a la Academia le agradan, podria darme el suficiente, y aun ayudarme para ello con la diligencia, y erudición de algún compañero, que juntando sus luces, y estudio, a mi ignorancia podra aclarar, y comprobar estos puntos.

Si no la gustasen; haré yo solo para mi el trabajo, con el fin de apagar mi curiosidad, y la de algun amigo, que se arrima a mi opinión.

Madrid.3.En. 1753

Luzan

Alvaro Soler DEl CAMPO

Conservador de la Real Armería. Patrimonio Nacional. Palacio Real.

C/Bailén s/n-28071 Madrid - E-mail: asoler.armeria@patrimonionacional.es

\section{BIBLIOGRAFÍA}

ABAdíA, I. (1793): Resumen sacado del Inventario General Histórico que se hizo en el año de 1793 de los arneses antiguos, armas blancas y de fuego, con otros efectos de la Real Armería del Rey Nuestro Señor. Madrid.

Almagro Gorbea, M. (Ed.) (1999): El Gabinete de Antigüedades de la Real Academia de la Historia. Madrid.

BocciA, L. G. CoElho, E. T. (1975): Armi bianche italiane. Milan.

Godoy, J. A. (1988): «Modelos de espadas y sables para el ejército y armada de Carlos III». Reales Sitios, $\mathrm{n}^{\circ}$ 98: 3-44.

Godoy, J. A. (1991): «Renaissance Arms and Armour from the Patrimonio Nacional». Resplandace of the Spanish Monarchy. Tapestries and Armor from the Patrimonio Nacional (Cat. Expo.) Nueva York: 95-164.

Godoy, J. A. (1992): «La Real Armería». Tapices y Armaduras del Renacimiento. Joyas de las colecciones reales. (Cat. expo.). Madrid-Barcelona: 99-193.

GYNGELL, D. S. H. (1959): Armourers Marks. London. 
MAIER, J. (2001): «La Real Academia de la Historia y el Patrimonio Histórico-Artístico Español».Tesoros de la Real Academia de la Historia. (Cat. expo. Palacio Real de Madrid. Abril-Julio de 2001). Madrid: 105-110.

Mann, J. (1962): European Arms and Armor. Volume II. Arms. Wallace Collection Catalogues. London.

Maravall, J. A. (1972): «Mentalidad burguesa e idea de la Historia en el siglo XVIII». Revista de Occidente, 107, XXXVI: 250-286.

Pinedo y Salazar, J. (1787): Historia de la insigne orden del Toyson de Oro. Madrid.

Roville, Guiame. (1553). Prima Pars Promptvari. Lyon, p. 70.

Tesoros de la Real Academia de la Historia. (Cat. expo. Palacio Real de Madrid. Abril-Julio de 2001). Ed. Martín Almagro Gorbea. Madrid, 2001.

Valencia de Don JuAn, Conde Viudo de (Crooke y Navarrot, J. B.) (1898): Catálogo HistóricoDescriptivo de la Real Armería de Madrid. Madrid. 